\title{
Syphilitic Gummata in the Central Nervous System: A Narrative Review and Case Report about a Noteworthy Clinical Manifestation
}

\author{
Lennart Barthel ${ }^{1,2, *}$, Susann Hetze ${ }^{1,2} \oplus$, Sarah Teuber-Hanselmann ${ }^{3}$, Valérie Chapot ${ }^{4}$ and Ulrich Sure ${ }^{1}$ \\ 1 Department of Neurosurgery, University Hospital of Essen, Hufelandstraße 55, 45147 Essen, Germany; \\ Susann.Hetze@uk-essen.de (S.H.); Ulrich.Sure@uk-essen.de (U.S.) \\ 2 Institute of Medical Psychology and Behavioral Immunobiology, University Hospital of Essen, \\ Hufelandstraße 55, 45147 Essen, Germany \\ 3 Institute of Neuropathology, University Hospital of Essen, Hufelandstraße 55, 45147 Essen, Germany; \\ Sarah.Teuber@uk-essen.de \\ 4 Institute of Medical Microbiology, University Hospital of Essen, Hufelandstraße 55, 45147 Essen, Germany; \\ Valerie.Chapot@uk-essen.de \\ * Correspondence: Lennart.Barthel@uk-essen.de; Fax: +49-201-723-5948
}

\section{check for} updates

Citation: Barthel, L.; Hetze, S.; Teuber-Hanselmann, S.; Chapot, V.; Sure, U. Syphilitic Gummata in the Central Nervous System: A Narrative Review and Case Report about a Noteworthy Clinical Manifestation. Microorganisms 2021, 9, 906. https:// doi.org/10.3390/

microorganisms 9050906

Academic Editor:

Sofia Costa-de-Oliveira

Received: 14 March 2021

Accepted: 21 April 2021

Published: 23 April 2021

Publisher's Note: MDPI stays neutral with regard to jurisdictional claims in published maps and institutional affiliations.

Copyright: (c) 2021 by the authors. Licensee MDPI, Basel, Switzerland. This article is an open access article distributed under the terms and conditions of the Creative Commons Attribution (CC BY) license (https:// creativecommons.org/licenses/by/ $4.0 /)$.

\begin{abstract}
Infection with Treponema pallidum is on the rise. In this narrative literature review, we show that the incidence of rare manifestations of syphilis, such as intracerebral gummata, is increasing and should be considered in the differential diagnosis of intracerebral lesions. With the exemplary case that we present here, we aim to raise awareness of the resurgence of this disease, which should be considered in the differential diagnosis of intracerebral lesions, especially for patients who have a risk profile for syphilis, and serological testing for T. pallidum prior to surgery should be discussed in order to avoid an unnecessary operation.
\end{abstract}

Keywords: neurosyphilis; syphilis; treponema pallidum; syphilitic gumma; central nervous system gumma; cerebral syphilitic gumma; brain syphilis

\section{Introduction}

Treponema pallidum is a Gram-negative, spiral-shaped bacterium (spirochete) of the family Spirochaetaceae that causes syphilis in humans [1,2]. The clinical manifestations of syphilis are diverse and depend on the stage of the disease, which can cause difficulty in distinguishing syphilis from other pathologies. After the Second World War, the worldwide incidence of syphilis decreased because of the efforts of the World Health Organization's global health programs and the central health policies of the former Soviet Union $[3,4]$. However, the incidence has been increasing in Eastern European and Western countries, particularly among men who have sex with men (MSM) [3,5]. Neurosyphilis can occur at any time after an initial infection [6,7]. On the basis of clinical examination and laboratory findings, its manifestations can be classified according to disease phase as early, early or late, and late [7]. Early-stage neurosyphilis can be asymptomatic, although the meninges are usually involved. Meningovascular involvement can be present in the early or late phase [7]. The late phase is characterized by general paresis or tabes dorsalis. Syphilitic gummata usually occur in tertiary syphilis, a stage in which blood vessels, the heart, and the nervous system are affected. However, syphilitic gummata are rare and therefore not integrated into the aforementioned neurosyphilis classification scheme. Although the incidence of syphilitic gummata is low, an increased number of patients with intracerebral gummata should be expected in the future due to the recent increase in the incidence of syphilis. To the best of our knowledge, there are no reliable data regarding the prevalence or incidence of neurosyphilitic gummata. We therefore conducted a literature review of articles concerning syphilitic gummata in the central nervous system that were published 
in the past 30 years. Our review confirms that the incidence of neurosyphilitic gummata is again on the rise. Additionally, we describe, as an example, the case of a 51-year-old man with newly diagnosed syphilis who presented with an intracerebral gumma that was initially suspected as a glioma.

\section{Case Presentation}

A 51-year-old man with leucocytic colitis presented in August 2016 with a one-month history of vertigo and blurry vision. He reported two episodes of tinnitus in February and April and a history of having sex with men. He was in a long-time monogamous relationship and his partner had no known previous infections. The patient had never been diagnosed with a sexually transmitted disease, nor had he received any serological testing for sexually transmitted diseases in the past. Active medications included antiandrogenic therapy for alopecia. A vestibular examination with Frenzel goggles showed spontaneous nystagmus. The remainder of his clinical examination was unremarkable. No skin or mucosal lesions were observed. Because of the inconspicuous clinical examination, no laboratory or instrumental testing was conducted, except imaging testing. Magnetic resonance imaging of the neurocranium showed a small right frontolateral dural-based contrast-enhancing lesion measuring approximately $1.5 \mathrm{~cm}$ in diameter with perifocal oedema (Figure 1). After consultation with our institutional interdisciplinary tumor board, surgery was recommended. During the operation, we noted that the lesion was supplied by cerebral vessels, had a firm leather-like consistency, and was not distinguishable from normal brain tissue- untypical for a glioma. Histological examination revealed fibrotic leptomeninges (Figure 2A) and infiltration of gliotic brain tissue by densely packed inflammatory cells surrounding necrotic foci (Figure 2B). Although these pathologies resembled granulomas to some extent, we did not identify any true granulomas. The infiltrates were embedded in collagenous tissue and comprised mainly plasma cells and lymphocytes accompanied by granulocytes, histiocytes, fibroblasts, epithelioid cells, and solitary multinucleated giant cells (Figure 2C). The blood vessels were surrounded by perivascular inflammatory cells but did not show any signs of vasculitis (i.e., necrosis or destruction and inflammation of the vessel walls) (Figure 2D). Bacterial and mycotic or mycobacterial pathogens were not detected in the histological specimen, nor by polymerase chain reaction (PCR), respectively. Additionally, immunohistochemical stainings for Toxoplasma species and T. pallidum were negative. Staining with antibodies against the glial fibrillary acidic protein (GFAP), p53, and IDH1-R132H were not suggestive of a brain tumor. Therefore, the histopathological diagnosis was necrotizing meningoencephalitis. Lumbar puncture for cerebrospinal fluid analysis was performed but did not show evidence of an infection. Although human immunodeficiency virus (HIV) infection was not detected, serum testing was positive for several treponemal tests (chemiluminescence assay (CLIA); T. pallidum hemagglutination assay (TPHA): 160,000 (reference, $<80$ titer); rapid plasma regain (RPR) test for anti-cardiolipin antibodies: 8 (reference, $<1$ titer)), as was cerebrospinal fluid testing (TPHA: 5000 (reference $<20$ titer); RPR: 1 (reference, $<1$ titer)). IgM antibodies for T. pallidum were positive (Treponema IgM: $51 \mathrm{IE} / \mathrm{mL}$ (reference $<20 \mathrm{IE} / \mathrm{mL}$ )). Prior to discharge on day 8 after surgery, the patient was referred to the dermatology department for a 21-day course of intravenous penicillin $\mathrm{G}$ (aqueous crystalline penicillin G, 24 million units per day, administered as 3-4 million units intravenous every $4 \mathrm{~h}$ for 10 days).

The T. pallidum serology parameters improved as well (CLIA: > 70; TPHA: 10,000; RPR: 4). Four months later, the patient had recovered completely. Serological parameters for T. pallidum were: CLIA: > 70; TPHA: 2560; RPR: < 1; IgM: $11 \mathrm{IE} / \mathrm{mL}$. 

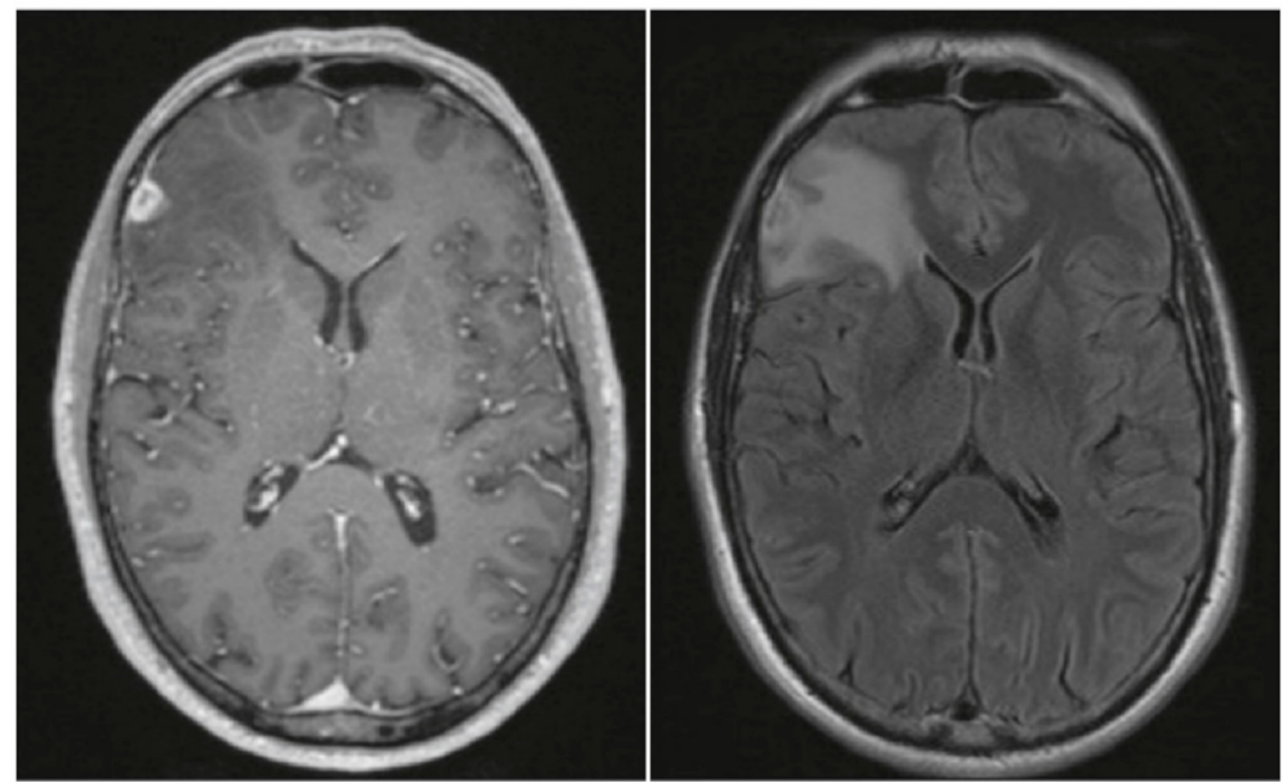

Figure 1. Magnetic resonance imaging of the neurocranium showed a small right frontolateral dural-based contrast-enhancing lesion measuring approximately $1.5 \mathrm{~cm}$ in diameter with perifocal oedema (left, T1-weighted sequence with contrast enhancement; right, fluid-attenuated inversion recovery (FLAIR) sequence).

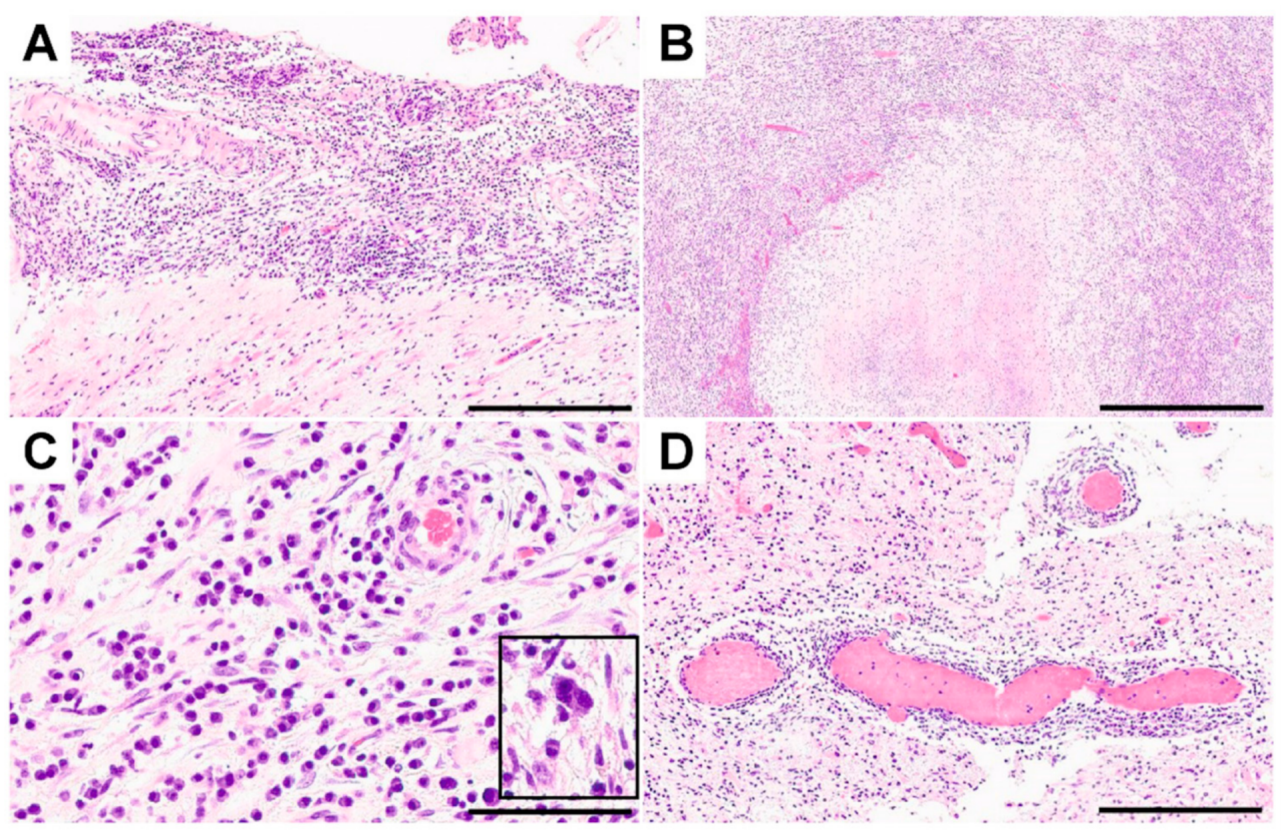

Figure 2. Fibrotic leptomeninges ((A) scale bar: $300 \mu \mathrm{m})$ and gliotic brain parenchyma ((B) scale bar: $500 \mu \mathrm{m}$ ) were observed, accompanied by foci of necrosis surrounded by densely packed inflammatory infiltrates comprised of lymphocytes, plasma cells, granulocytes, histiocytes, fibroblasts ((C) scale bar: $50 \mu \mathrm{m}$ ), and solitary multinucleated giant cells (inset in C). Leptomeningeal and intraparenchymal blood vessels showed perivascular inflammation without signs of vasculitis ((D) scale bar: $300 \mu \mathrm{m})$.

\section{Review}

We have identified and extracted data from 49 neurosyphilitic gumma cases in addition to our case since 1990. An additional report describes six cases from the U.S. However, no conclusions can be drawn from the patient-specific information (report from 1992) [8]. In total, 8 of the 50 cases were women (mean age, 49.6 years; range, 37-65) and 42 were men (information about age was given in 39 cases: mean age, 45.5 years; range, 20-75). For 
two men, no age was reported; the age of one man was described as "in his 30s." Among the 42 men, 5 were reported to be heterosexual (mean age, 46.6 years; range, 41-54). MSM was reported for four cases (mean age, 50 years; range, 42-61), and two of them were human immunodeficiency virus (HIV)-positive aged 42 and 46 years. Otherwise, 33 had no sexual preference reported. Overall, 14 of the men were HIV-positive (33.3\%), and 2 of the 5 heterosexual reported men were HIV-positive. Among the men whose sexual preference was not reported, 14 were HIV-positive (42.42\%). None of the women were reported to be HIV-positive, although HIV status was not reported for one case. Surgery was performed in 28 patients $(56 \%)$, and 21 received conservative treatment only $(42 \%)$. Information about surgery was not reported in one patient. In Table 1 are all 50 cases listed by location of the gumma, sex, MSM, age, HIV status, and country of the report. Many cerebral syphilitic gummata were reported in North America at the beginning of the 1990s. Since 2000, cases have been reported in Europe, and an increase in the overall number of reported cases began in 2016, predominately in China and Japan. In Table 2, it is shown how the patients clinically presented, whether the patients underwent an operation, which drug treatment was carried out, and the clinical outcome of the patients. As is typical of syphilis, the clinical symptoms varied widely, are difficult to divide into individual categories, and depend on the gumma's localization. In most cases, the therapy regimen was carried out with IV penicillin, with differences in dosage and therapy duration (details in Table 2). Table 3 lists the diagnostic results (histological, CSF, and neuroimaging) for the corresponding cases. In the multitude of histological findings, inflammatory processes were demonstrated, often accompanied by increased vascularization. Strain analyzes for T. pallidum were not always positive. White blood cells were often present and increased or reactivated VDRL or a positive T. pallidum antibody index. Increased protein levels and pleocytosis were also often present. On imaging, syphilitic gummata presented mostly solid and contrasted medium, with perifocal edema and signs of inflammatory processes (details in Table 3).

Table 1. Listed are all identified cases between the years 1990 and 2021. Ordered by years of the report. The location of the syphilitic gumma, sex, men who have sex with men (MSM), age, human immunodeficiency virus (HIV) status, and country of the report are presented. If no information was available for one of the categories, the table's casket was left blank. (Abbreviations: f, feminine; HIV, human immunodeficiency virus; $\mathrm{m}$, masculine.).

\begin{tabular}{|c|c|c|c|c|c|c|c|c|}
\hline \# of Case & Location & Sex & MSM & Age & HIV & $\begin{array}{l}\text { Year of } \\
\text { Report }\end{array}$ & Country & Ref. \\
\hline 1 & Frontal lobe; thoracic vertebrae & $\mathrm{f}$ & & 37 & no & 2021 & U.S. & [9] \\
\hline 2 & Frontal lobe & $\mathrm{m}$ & & 45 & & 2019 & China & [10] \\
\hline 3 & $\begin{array}{l}\text { Thoracic medullary Th10; cauda } \\
\text { equina at the } 3 / 4 \text { lumbar level }\end{array}$ & $\mathrm{m}$ & & "In his 30s" & no & 2019 & Australia & [11] \\
\hline 4 & $\begin{array}{l}\text { Multiple loci cerebellar } \\
\text { and medullary }\end{array}$ & $\mathrm{m}$ & & 22 & no & 2019 & China & [12] \\
\hline 5 & Frontal and temporal lobe & $\mathrm{m}$ & & 47 & no & 2019 & Japan & [13] \\
\hline 6 & $\begin{array}{c}\text { Thoracal intra-/extramedullary } \\
\text { T8 level }\end{array}$ & $\mathrm{f}$ & & 45 & no & 2019 & China & [14] \\
\hline 7 & Frontal lobe & $\mathrm{m}$ & & 37 & & 2018 & China & [15] \\
\hline 8 & Frontal lobe & $\mathrm{m}$ & & 62 & & 2018 & China & [15] \\
\hline 9 & Frontal lobe & $\mathrm{m}$ & & 66 & & 2018 & China & [15] \\
\hline 10 & Temporal lobe & $\mathrm{m}$ & & 62 & no & 2018 & Japan & [16] \\
\hline 11 & Temporal lobe & $\mathrm{m}$ & no & 44 & yes & 2018 & Japan & [17] \\
\hline 12 & Temporal & $\mathrm{m}$ & & 36 & no & 2018 & Japan & [18] \\
\hline 13 & Frontal lobe & $\mathrm{f}$ & & 50 & & 2018 & Japan & [19] \\
\hline 14 & Medullary L4 & $\mathrm{m}$ & & 61 & & 2017 & China & [20] \\
\hline
\end{tabular}


Table 1. Cont.

\begin{tabular}{|c|c|c|c|c|c|c|c|c|}
\hline \# of Case & Location & Sex & MSM & Age & HIV & $\begin{array}{l}\text { Year of } \\
\text { Report }\end{array}$ & Country & Ref. \\
\hline 15 & Frontal lobe & $\mathrm{m}$ & & 62 & & 2017 & China & [21] \\
\hline 16 & Brain stem & $\mathrm{m}$ & no & 41 & no & 2017 & China & [22] \\
\hline 17 & Optic nerve & $\mathrm{m}$ & & 36 & yes & 2016 & U.S. & [23] \\
\hline 18 & Parietal lobe & $\mathrm{m}$ & & 56 & no & 2016 & China & [24] \\
\hline 19 & Intramedullary C5 level & $\mathrm{f}$ & & 65 & no & 2016 & China & [25] \\
\hline 20 & Frontal lobe & $\mathrm{m}$ & & 21 & yes & 2016 & Japan & [26] \\
\hline 21 & Occipital lobe & $\mathrm{m}$ & & 53 & & 2016 & Greece & [27] \\
\hline 22 & Frontal lobe & $\mathrm{m}$ & yes & 51 & no & 2016 & Germany & This case \\
\hline 23 & Parietal lobe & $\mathrm{m}$ & & 40 & yes & 2014 & Switzerland & [28] \\
\hline 24 & Frontal lobe & $\mathrm{f}$ & & 59 & no & 2013 & $\begin{array}{l}\text { South } \\
\text { Korea }\end{array}$ & [29] \\
\hline 25 & Parietal & $\mathrm{m}$ & & 38 & no & 2013 & China & {$[30]$} \\
\hline 26 & Pons & $\mathrm{m}$ & & 26 & yes & 2012 & Brazil & [31] \\
\hline 27 & Cavernous sinus & $\mathrm{f}$ & & 62 & no & 2011 & $\begin{array}{l}\text { South } \\
\text { Africa }\end{array}$ & {$[32]$} \\
\hline 28 & Basal ganglia; temporal lobe & $\mathrm{m}$ & & 45 & no & 2011 & China & [33] \\
\hline 29 & Cerebrum & $\mathrm{f}$ & & 40 & no & 2009 & $\begin{array}{l}\text { South } \\
\text { Korea }\end{array}$ & {$[34]$} \\
\hline 30 & Occipital lobe & $\mathrm{m}$ & yes & 61 & no & 2008 & U.S. & [35] \\
\hline 31 & Frontal lobe & $\mathrm{m}$ & & 20 & yes & 2008 & Brazil & [36] \\
\hline 32 & Frontal lobe & $\mathrm{m}$ & yes & 46 & yes & 2008 & Canada & [37] \\
\hline 33 & Temporal lobe & $\mathrm{m}$ & no & 43 & no & 2008 & Australia & [38] \\
\hline 34 & Parietal lobe & $\mathrm{m}$ & & 42 & yes & 2007 & Portugal & [39] \\
\hline 35 & Parietotemporal & $\mathrm{m}$ & no & 54 & & 2007 & U.S. & {$[40]$} \\
\hline 36 & Frontal lobe & $\mathrm{m}$ & yes & 42 & yes & 2005 & Belgium & {$[41]$} \\
\hline 37 & Corpus callosum & $\mathrm{m}$ & & 42 & no & 2005 & U.S. & [42] \\
\hline 38 & $\begin{array}{l}\text { Pons and middle cerebellar } \\
\text { peduncle }\end{array}$ & $\mathrm{m}$ & no & 51 & yes & 2003 & Brazil & [43] \\
\hline 39 & Temporo-parietal & $\mathrm{m}$ & & 42 & yes & 2002 & Israel & [44] \\
\hline 40 & Temporo-occipital & $\mathrm{m}$ & & 75 & & 1999 & Japan & [45] \\
\hline 41 & Frontal lobe & $\mathrm{m}$ & & 47 & no & 1996 & U.S. & [46] \\
\hline 42 & Optic tract, temporal lobe & $\mathrm{f}$ & & 39 & no & 1995 & Japan & [47] \\
\hline 43 & Cerebellar, temporal lobe & $\mathrm{m}$ & & 51 & & 1995 & Japan & {$[48]$} \\
\hline 44 & Parieto-occipital, cerebellum & $\mathrm{m}$ & & 29 & yes & 1994 & U.S. & [49] \\
\hline 45 & $\begin{array}{c}\text { Pontomesencephalic region; } \\
\text { choroidal fissure }\end{array}$ & $\mathrm{m}$ & & 69 & no & 1994 & U.S. & {$[50]$} \\
\hline 46 & "Cerebral" & $\mathrm{m}$ & & & yes & 1992 & U.S. & {$[51]$} \\
\hline 47 & "Cerebral" & $\mathrm{m}$ & & & yes & 1992 & U.S. & {$[51]$} \\
\hline 48 & Tuber cinereum & $\mathrm{m}$ & & 37 & & 1991 & U.S. & {$[52]$} \\
\hline 49 & Midbrain and thalamus & $\mathrm{m}$ & & 27 & & 1991 & U.S. & [53] \\
\hline 50 & Optic nerve & $\mathrm{m}$ & & 68 & & 1990 & U.S. & [54] \\
\hline
\end{tabular}




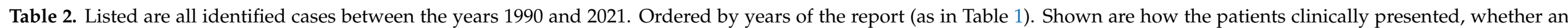
operation was carried out, which drug treatment was carried out, and the outcome. (Abbreviations: IM, intramuscular injection; IV, intravenous therapy.).

\begin{tabular}{|c|c|c|c|c|c|}
\hline \# of Case & Clinical Appearance & Surgery & Treatment & Outcome & Ref. \\
\hline 1 & $\begin{array}{l}\text { Seizures, left-sided weakness, urinary incontinence, } \\
\text { mild photophobia, ataxia, and headache. }\end{array}$ & Yes & Benzathine penicillin G daily; dexamethasone. & & [9] \\
\hline 2 & Headache and left-sided weakness. & Yes & $\begin{array}{c}\text { 14-day course of IV penicillin ( } 2.5 \text { million } \mathrm{U} \\
\text { administered every } 4 \mathrm{~h} \text { ) followed by a three-week } \\
\text { course of IM of benzathine penicillin ( } 2.4 \text { million } \mathrm{U} \\
\text { administered once per week). }\end{array}$ & $\begin{array}{l}\text { Myodynamia of the left limbs } \\
\text { gradually improved. }\end{array}$ & [10] \\
\hline 3 & $\begin{array}{l}\text { Rapidly progressive right lower limb monoparesis } \\
\text { associated with sphincter and erectile dysfunction; } \\
\text { impaired sensation in the right leg, with reduced } \\
\text { anal tone and saddle anesthesia. }\end{array}$ & Yes & IV benzylpenicillin. & $\begin{array}{l}\text { Near complete neurological recovery } \\
\text { after three months. }\end{array}$ & [11] \\
\hline 4 & $\begin{array}{c}\text { Progressive right lower limb weakness with tremor, } \\
\text { and headache. }\end{array}$ & No & $\begin{array}{l}\text { IV penicillin G at } 24 \text { million units daily divided into six } \\
\text { doses was given for a total of } 21 \text { days, along with three } \\
\text { weekly IM of benzathine penicillin G (BPG, } 2.4 \text { million } \\
\text { units); oral prednisolone ( } 40 \mathrm{mg} \text { ) was also prescribed } \\
24 \mathrm{~h} \text { before the start of penicillin for three days. }\end{array}$ & $\begin{array}{l}\text { Complete neurological recovery after } \\
\text { three weeks. }\end{array}$ & [12] \\
\hline 5 & $\begin{array}{l}\text { Generalized tonic-clonic seizures; syphilitic roseola } \\
\text { was observed on the skin in the hypogastric region. }\end{array}$ & no & $\begin{array}{l}\text { Amoxicillin per os } 1500 \mathrm{mg} / \text { day followed by penicillin } \\
\text { G IV } 24 \times 10^{6} \mathrm{U} \text { for } 14 \text { days. }\end{array}$ & Completely recovered. & [13] \\
\hline 6 & $\begin{array}{l}\text { Revealed muscle strength of grade } 3 / 5 \text { in right } \\
\text { lower extremities and loss of superficial sensation of } \\
\text { grade } 3 / 10 \text { below the umbilicus on the left side; } \\
\text { grade } 3 \text { ankle and knee hyperreflexia on the right } \\
\text { side; positive Babinski sign and Chaddock sign. }\end{array}$ & yes & $\begin{array}{l}\text { Penicillin G (IV } 19.6 \text { million U/day, and } 4.9 \text { million } U \\
\text { QID) for } 14 \text { days, then IM benzathine penicillin } G \\
\text { (2.4 million U QW) for } 21 \text { days. }\end{array}$ & $\begin{array}{l}\text { Completely recovered after } \\
\text { three months. }\end{array}$ & [14] \\
\hline 7 & Dizziness for $\sim 15$ days. & no & $\begin{array}{l}\text { 14-day IV penicillin ( } 2.4 \text { million U every } 4 \mathrm{~h} \text { ) followed } \\
\text { by three weeks of IM benzathine penicillin } \\
\text { ( } 2.4 \text { million } \mathrm{U} \text {, once per week). }\end{array}$ & $\begin{array}{l}\text { Complete recovery after } \\
\text { four months. }\end{array}$ & [15] \\
\hline 8 & Speech arrest for $10 \mathrm{~h}$, clear consciousness. & yes & & Complete recovery after six months. & [15] \\
\hline 9 & $\begin{array}{c}\text { Decreasing right eye vision and headache since } \\
\sim 50 \text { days ago. }\end{array}$ & yes & & & [15] \\
\hline 10 & Headache. & yes & & & [16] \\
\hline 11 & Severe headache, nausea, and vomiting. & yes & 14 days of IV ceftriaxone 2 g every $24 \mathrm{~h}$. & Completely recovered. & [17] \\
\hline
\end{tabular}


Table 2. Cont.

\begin{tabular}{|c|c|c|c|c|c|}
\hline \# of Case & Clinical Appearance & Surgery & Treatment & Outcome & Ref. \\
\hline 12 & $\begin{array}{l}\text { Hearing loss in right ear and right-side facial } \\
\text { paralysis since two weeks ago. }\end{array}$ & no & “2015 U.K. national guidelines”. & $\begin{array}{l}\text { After two weeks: facial nerve palsy } \\
\text { improved markedly; hearing loss } \\
\text { improved gradually. }\end{array}$ & [18] \\
\hline 13 & $\begin{array}{l}\text { Headache, right-sided hearing loss, tinnitus, and } \\
\text { vertigo since three months ago. }\end{array}$ & no & IV penicillin G. & & [19] \\
\hline 14 & $\begin{array}{l}\text { Worsening pain and numbness in both lower legs } \\
\text { for four weeks, started one year ago. }\end{array}$ & yes & & & [20] \\
\hline 15 & $\begin{array}{l}\text { Speech disturbance and a mild headache since } \\
\qquad 10 \text { days ago. }\end{array}$ & yes & $\begin{array}{l}\text { Penicillin G IV daily ( } 24 \text { million units for } 14 \text { days), } \\
\text { followed by IM benzathine penicillin G ( } 2.4 \text { million } \\
\text { units three-weekly). }\end{array}$ & "Improving gradually". & [21] \\
\hline 16 & $\begin{array}{l}\text { Headache, swallowing difficulties, and dysarthria } \\
\text { for four months, and vomiting for a month and a } \\
\text { half; progressive right facial and neck numbness for } \\
\text { two years; dysarthria; right Babinski sign positive. }\end{array}$ & no & IV penicillin G ( 24 million units per day). & Complete recovery after two months. & [22] \\
\hline 17 & Decreased vision, left eye. & no & 14 days of IV penicillin. & Vision improved. & [23] \\
\hline 18 & $\begin{array}{l}\text { Mild headache; twitch and right limb } \\
\text { sustained shaking. }\end{array}$ & yes & $\begin{array}{l}\text { IV penicillin G ( } 24 \text { million units per day for } 12 \text { days), } \\
\text { followed by IM benzathine penicillin G ( } 2.4 \text { million } \\
\text { units three-weekly). }\end{array}$ & & [24] \\
\hline 19 & $\begin{array}{l}\text { Paresthesia in both upper extremities and weakness; } \\
\text { two-month history of neck-shoulder-back pain. }\end{array}$ & yes & IV penicillin G (24 million units/day) for 14 days. & $\begin{array}{l}\text { After } 29 \text { months: pain completely } \\
\text { relieved; sensorimotor dysfunctions } \\
\text { partially improved; sensory } \\
\text { disturbance remained; muscle } \\
\text { strength legs improved. }\end{array}$ & [25] \\
\hline 20 & $\begin{array}{l}2 \mathrm{~h} \text { loss of consciousness; prior: uncomfortable } \\
\text { feeling at the back of his head and neck and eye } \\
\text { fatigue that lasted for one week. }\end{array}$ & no & $\begin{array}{l}\text { IV benzylpenicillin ( } 24 \text { million units/day) for } 14 \\
\text { consecutive days. }\end{array}$ & Complete recovery after two months. & [26] \\
\hline 21 & Rapidly deteriorating gait disorder. & yes & "Per os penicillin". & Complete recovery. & [27] \\
\hline 22 & $\begin{array}{l}\text { One-month history of vertigo and blurry vision; } \\
\text { two episodes of tinnitus. }\end{array}$ & yes & $\begin{array}{c}\text { IV penicillin G ( } 24 \text { million units per day, 3-4 million } \\
\text { units every } 4 \mathrm{~h} \text { ) for } 10 \text { days. }\end{array}$ & $\begin{array}{l}\text { Complete recovery after } \\
\text { four months. }\end{array}$ & $\begin{array}{l}\text { This } \\
\text { case }\end{array}$ \\
\hline 23 & $\begin{array}{l}\text { Persistent fatigue, excessive sweating and pain in } \\
\text { the right thorax, slight paresthesia of the right hand, } \\
\text { and headaches. }\end{array}$ & yes & IV penicillin $\mathrm{G}(6 \times 4$ Mio U/day) for 14 days. & & [28] \\
\hline
\end{tabular}


Table 2. Cont.

\begin{tabular}{|c|c|c|c|c|c|}
\hline \# of Case & Clinical Appearance & Surgery & Treatment & Outcome & Ref. \\
\hline 24 & Speech disturbance/dysarthria. & yes & Ceftriaxone IV daily dose of $2 \mathrm{~g}$ for 14 days. & $\begin{array}{l}\text { Completely recovered after } 15 \\
\text { months. }\end{array}$ & [29] \\
\hline 25 & Headache and emesis for 15 days. & yes & & $\begin{array}{l}\text { "Symptoms are improving } \\
\text { gradually". }\end{array}$ & [30] \\
\hline 26 & $\begin{array}{l}\text { Four-month history of fever, weight loss, dizziness, } \\
\text { diarrhea, tremors, and paresthesia, disorientation, } \\
\text { pyramidal and extrapyramidal symptoms, and } \\
\text { multiple cutaneous non-pruriginous cicatricial } \\
\text { lesions affecting the chest and inferior limbs. }\end{array}$ & no & $\begin{array}{l}\text { IV crystalline penicillin }\left(24 \times 10^{6} \text { units/day) for }\right. \\
\qquad 14 \text { days. }\end{array}$ & "Significant clinical improvement". & [31] \\
\hline 27 & $\begin{array}{l}\text { Two-week history of painful ophthalmoplegia and a } \\
\text { complete left ptosis, signs of cavernous sinus } \\
\text { syndrome, with left sided III, IV, V1, V2, and VI } \\
\text { cranial nerve palsies. }\end{array}$ & no & $\begin{array}{l}\text { IV crystalline penicillin G ( } 24 \text { million units per day) for } \\
\text { two weeks, followed by } 2.4 \text { million units of IM } \\
\text { penicillin administered weekly for three weeks (total } \\
\quad 7.2 \text { million units). }\end{array}$ & $\begin{array}{l}\text { Cranial nerves: After three weeks, } \\
\text { full recovery in III, IV, V1, and V2, } \\
\text { and partial recovery in } \\
\text { cranial nerve VI. }\end{array}$ & [32] \\
\hline 28 & $\begin{array}{l}\text { Eight-day history of right-sided vision loss, slurred } \\
\text { speech, incoordination of his right arm and leg, and } \\
\text { imbalance ad admission. }\end{array}$ & yes & $\begin{array}{l}\text { IV penicillin G } 14 \text { days, followed by three-weekly IM } \\
\text { shots of benzathine penicillin } G \\
\text { ( } 2.4 \text { million units). }\end{array}$ & $\begin{array}{l}\text { One-month follow-up: gait and use } \\
\text { of right hand improved dramatically; } \\
\text { right-sided visual loss persisted. }\end{array}$ & [33] \\
\hline 30 & $\begin{array}{l}\text { Two-month history of progressively worsening } \\
\text { altered mental status and intermittent seizures } \\
\text { characterized by the déjà vu phenomena; left } \\
\text { homonymous hemianopsia. }\end{array}$ & yes & & & [35] \\
\hline 31 & Single episode of a tonic-clonic seizure. & yes & $\begin{array}{l}\text { IV crystalline penicillin } \mathrm{G} \text { ( } 24 \text { million units) daily for } \\
\qquad 14 \text { days. }\end{array}$ & & [36] \\
\hline 32 & Eight-week history of left frontal headaches. & no & "Intravenous penicillin". & No further symptoms. & [37] \\
\hline 33 & $\begin{array}{l}\text { Two-month history of worsening generalized } \\
\text { headaches, nausea, and peculiar speech. }\end{array}$ & yes & "Intravenous penicillin". & Full clinical recovery. & [38] \\
\hline 34 & Generalized seizure. & no & $\begin{array}{l}\text { IV penicillin G; after } 10 \text { days, the patient refused } \\
\text { further treatment. }\end{array}$ & $\begin{array}{l}\text { After two-month asymptomatic } \\
\text { period, follow-up MRI: residual focal } \\
\text { contrast enhancement, marked } \\
\text { reduction of perilesional edema, and } \\
\text { normal signal on diffusion weighted } \\
\text { imaging (DWI). }\end{array}$ & [39] \\
\hline
\end{tabular}


Table 2. Cont.

\begin{tabular}{|c|c|c|c|c|c|}
\hline \# of Case & Clinical Appearance & Surgery & Treatment & Outcome & Ref. \\
\hline 35 & $\begin{array}{l}\text { "Altered mental status," rhabdomyolysis, and } \\
\text { hypernatremia; confused, disoriented, and agitated; } \\
\text { "speech was incoherent, his mood anxious, and his } \\
\text { affect inappropriate". }\end{array}$ & no & & $\begin{array}{l}\text { The patient died eight days after } \\
\text { admission; the diagnosis of } \\
\text { neurosyphilitic gumma was made } \\
\text { post-mortem. }\end{array}$ & [40] \\
\hline 36 & $\begin{array}{l}\text { Fever, headache for two and a half months, and } \\
\text { hearing loss since one week before }\end{array}$ & no & IV penicillin $G$ and ampicillin for three weeks & Complete recovery after three weeks & [41] \\
\hline 37 & $\begin{array}{l}\text { Frequent falling, visual hallucinations, headaches, } \\
\text { diminished appetite, and prominent weight loss } \\
\text { over a period of several months; cachectic and } \\
\text { minimally interactive; prominent abulia, } \\
\text { psychomotor retardation, and tremulousness of } \\
\text { bilateral upper extremities; diminished } \\
\text { proprioception with a shuffling gait }\end{array}$ & yes & & Patient died during hospital stay & [42] \\
\hline 38 & $\begin{array}{l}\text { Three-month history of progressive visual decline } \\
\text { in the right eye }\end{array}$ & no & IV penicillin ( 24 million units/day) for 21 days & Lost to follow-up & [43] \\
\hline 39 & Grand mal seizure; ataxia & yes & Treatment for tuberculosis & $\begin{array}{l}\text { Died after three weeks; post-mortem } \\
\text { diagnosis of syphilis }\end{array}$ & [44] \\
\hline 40 & 10-day history of headache & yes & $\begin{array}{l}\text { IV penicillin G: Skin eruption; switch to oral } \\
\text { erythromycin for } 28 \text { days }\end{array}$ & Recovery & [45] \\
\hline 41 & Generalized seizure & no & IV phenytoin and high-dose penicillin $\mathrm{G}$ for 21 days & Recovery & [46] \\
\hline 42 & $\begin{array}{c}\text { Visual impairment worsening rapidly over one } \\
\text { week; left upper quadrantanopsia, diplopia, slight } \\
\text { hemiparesis, and hypesthesia on the left side; } \\
\text { bilateral optic atrophy }\end{array}$ & yes & $\begin{array}{l}\text { IV penicillin } \mathrm{G}\left(24 \times 10^{6} \mathrm{U} / \text { day IV) plus probenecid for }\right. \\
14 \text { days, followed by procaine penicillin } \mathrm{G} \\
\left(2.4 \times 10^{6} \mathrm{U} / \text { week } \mathrm{IM}\right)\end{array}$ & $\begin{array}{l}\text { Rigidity in left upper extremity } \\
\text { resolved; left upper homonymous } \\
\text { quadrantanopsia remained }\end{array}$ & [47] \\
\hline 43 & $\begin{array}{c}\text { Four-month history of headache; diplopia for three } \\
\text { months; vertigo; cerebellar ataxia; abducens } \\
\text { nerve paresis }\end{array}$ & yes & $\begin{array}{l}\text { IV penicillin } \mathrm{G}\left(12 \times 10^{6} \mathrm{U} / \text { day) for } 10 \text { days }\right. \\
\left.\text { (total } 120 \times 10^{6} \mathrm{U}\right)\end{array}$ & $\begin{array}{l}\text { Cerebellar ataxia gradually } \\
\text { improved; right abducens nerve } \\
\text { paresis remained unchanged }\end{array}$ & [48] \\
\hline
\end{tabular}

Three years before: history of right-sided weakness

for six months, changes in mental status for three months, one seizure one week before admission, problems with swallowing for one week;

Cefotaxime $2 \mathrm{~g}$ IV every $6 \mathrm{~h}$ for 11 days, followed by IV penicillin $\mathrm{G}\left(12 \times 10^{6} \mathrm{U} /\right.$ day $)$ for 10 days; subsequently, amphotericin $B$ and ceftazidime (because of progressive neurological deterioration)
None of the lesions resolved with treatment; four days before death, occlusive hydrocephalus 
Table 2. Cont.

\# of Case Clinical Appearance

Intermittent diplopia, slurred speech, right-sided weakness, and gait unsteadiness;

after therapy (five months later): Mild worsening of the right-sided hemiparesis

\section{Treatment}

Allergy to penicillin: two-week IV ceftriaxone (1

$\mathrm{g} /$ day), followed by 30 days of oral doxycycline (100 mg twice a day);

no second treatment five months after initial treatment: skin tests for penicillin al IV penicillin ( 4 million $\mathrm{U}$ every $4 \mathrm{~h}$ )

\section{Outcome}

Ref.

Five months after initial therapy:

Mild worsening of hemiparesis;

at follow-up six months after last

therapy (penicillin): Remained

neurologically stable; findings on a

repeated lumbar puncture were

$$
\text { normal }
$$

\begin{tabular}{|c|c|c|c|c|c|}
\hline 46 & Seizure disorder & yes & "High-dose" IV penicillin & & [51] \\
\hline 47 & Seizure disorder & no & "High-dose" IV penicillin & & [51] \\
\hline 48 & $\begin{array}{l}\text { Headache for three months; mild ataxia, } \\
\text { intermittent low-grade fever, skin rashes, cervical } \\
\text { lymph node enlargement, conjunctivitis, and } \\
\text { progressively decreased libido }\end{array}$ & & $\begin{array}{l}\text { Initial diagnosis sarcoidosis: prednisone; after second } \\
\text { lumbar puncture and diagnosis of syphilis: IV } \\
\text { penicillin G ( } 24 \text { million units per day) for } 10 \text { days. }\end{array}$ & $\begin{array}{l}\text { Three months after therapy: } \\
\text { Neurological examination was } \\
\text { normal; left hemi-ataxia resolved }\end{array}$ & [52] \\
\hline 49 & $\begin{array}{l}\text { Dorsal midbrain syndrome, cognitive dysfunction, } \\
\text { and a left peripheral seventh nerve palsy }\end{array}$ & no & "Intravenous penicillin" & & [53] \\
\hline
\end{tabular}




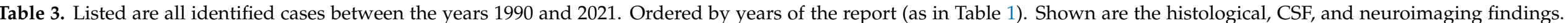

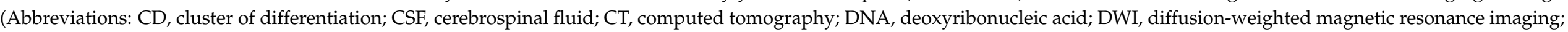

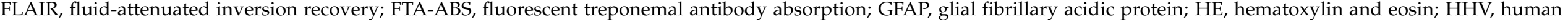

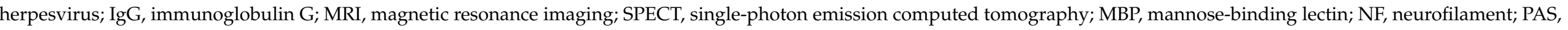

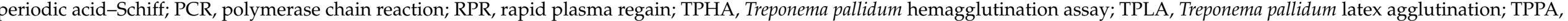
Treponema pallidum particle agglutination assay; TRUST, toluidine red unheated serum test; VDRL, Venereal Disease Research Laboratory).

\begin{tabular}{|c|c|}
\hline \# of Case & Histology \\
\hline 1 & $\begin{array}{l}\text { Focal chronic dural inflammation and a reactive neocortex with chronic } \\
\text { inflammation and rare spirochetes. }\end{array}$ \\
\hline 2 & $\begin{array}{c}\text { Large quantity of inflammatory cell infiltration containing lymphocytes, } \\
\text { neutrophils, and necrosis. }\end{array}$ \\
\hline 3 & $\begin{array}{l}\text { Initial Warthin-Starry staining for spirochetes, Ziehl-Neelsen staining for } \\
\text { atypical bacteria, and periodic acid-Schiff staining for fungi were } \\
\text { negative; retrospective immunoperoxidase stains returned positive and } \\
\text { revealed scattered spirochetes. }\end{array}$ \\
\hline
\end{tabular}

Routine examination, biochemical indexes: normal; TPPA: positive.

\section{CSF}

\section{Neuroimaging}

MRI: cerebral edema of the frontoparietal lobes; nodular contrast enhancement (T1).

Edema around the lesion in MRI and CT.

CT: low-density lesion; homogeneous enhancement with contrast.

MRI: isointensity on T1; long T2 nodular signal shadow; somewhat higher T2-FLAIR signal; high signal in diffusion-weighted imaging.

MRI: lobulated contrast enhancing intramedullary mass at level T10.

White blood cells: 84 cells $/ \mathrm{mL}$; total protein level: $2.08 \mathrm{~g} / \mathrm{L}$; glucose level $2.95 \mathrm{mmol} / \mathrm{L}$; TRUST: positive (1:4)

MRI: multiple dural-based enhancing masses;

rregular ring-enhancing lesion, central hypointense surrounding edema; enhanced nodules:

homogeneous-enhancing or ring-enhancing.

Cell count: 199/mL; glucose: 6

$\mathrm{mg} / \mathrm{dL}$; protein: $116 \mathrm{mg} / \mathrm{dL}$; positive TPHA and

MRI: multiple mass lesions, enhanced and adjacent to the dura, left cerebral hemisphere.

FTA-ABS-immunoglobulin G.

Granulomatous inflammation with small areas of caseous necrosis,

multinucleated giant cells infiltration, surrounded by large numbers of

lymphocytes and small numbers of neutrophils; swelling and hyperplasia

of some vascular endothelial cells with massive infiltration of

lymphocytes and plasma cells around the blood vessels;

immunohistochemistry: immunopositivity with glial fibrillary acidic protein, myelin basic protein, neurofilament protein, CD3, CD45RO, and

CD68, but was negative for periodic acid-Schiff and CD56; acid-fast

staining: negative; further Warthin-Starry staining confirmed spirochetes.

MRI: irregular nodule at T8 level intradural-extramedullary and intramedullary, slightly hyperintense (T1), heterogeneously hyperintense signal (T2), significantly and homogeneously enhanced with contrast. 
Table 3. Cont.

\begin{tabular}{|c|c|c|c|c|}
\hline \# of Case & Histology & CSF & Neuroimaging & Ref. \\
\hline 7 & & $\begin{array}{l}\text { Protein: } 97.3 \mathrm{mg} / \mathrm{dL} \text {; white blood } \\
\text { cells: } 84 \times 10^{6} / \mathrm{L} \text {; RPR: positive; } \\
\text { TPPA: positive. }\end{array}$ & $\begin{array}{l}\text { MRI: slightly abnormal lamellar and longer T1, T2 } \\
\text { signal shadow; contrast enhancement: lesion patchy } \\
\text { enhancement, adjacent meninges slightly thickened } \\
\text { and enhanced. }\end{array}$ & [15] \\
\hline 8 & $\begin{array}{l}\text { HE staining: necrotic with infiltration of inflammatory cells, glial } \\
\text { proliferation in the periphery; GFAP staining: small amount of glial } \\
\text { proliferation around necrotic foci; Ki67 staining: higher proliferative } \\
\text { activity around the necrotic lesions; P53 staining: negative peripheral P53. }\end{array}$ & & $\begin{array}{l}\text { MRI: slightly long T1 and a long T2 nodular signal } \\
\text { shadow left cerebral falx, slightly high T2- FLAIR } \\
\text { and DWI signal; edema. } \\
\text { CT: low-density-area left frontal lobe, } \\
\text { ventricular compression. }\end{array}$ & [15] \\
\hline 9 & $\begin{array}{l}\text { Argyrophilic staining: negative; HE staining: necrotic with infiltration of } \\
\text { inflammatory cells, glial proliferation in the periphery; GFAP staining: } \\
\text { small amount of glial proliferation around necrotic foci; Ki67 staining: } \\
\text { higher proliferative activity around the necrotic lesions; P53 staining: } \\
\text { negative peripheral P53. }\end{array}$ & TPPA: positive; RPR: positive. & $\begin{array}{l}\text { MRI: irregular clumping, high-signal mixed with } \\
\text { low-signal foci frontal lobe, unclear border, } \\
\text { surrounded by a large, low-signal shadow, } \\
\text { ventricle re-compressed. }\end{array}$ & [15] \\
\hline 10 & Immunohistochemical staining revealed numerous spirochetes. & 2.2-fold higher RPR levels. & $\begin{array}{l}\text { Contrast-enhanced T1-weighted, fluid-attenuated } \\
\text { inversion recovery image reveal ring-enhanced }\end{array}$ & [16] \\
\hline
\end{tabular}

Nonspecific inflammatory granuloma with central necrosis; T. pallidum immunohistochemical stain: clearly stained as helical-shaped in the 11 granuloma specimen (two different T. pallidum-specific PCR (targeting polA and TpN47) for homogenized specimens were positive; T. pallidum DNA was identified.
Cells: $12 / \mathrm{mm}^{3}$; glucose: $98 \mathrm{mg} / \mathrm{dL}$; protein: $90 \mathrm{mg} / \mathrm{dL}$; TPLA: negative

RPR: negative.

MRI: nodule with ring enhancement; high-intensity area in $\mathrm{T} 2$

SPECT: weak uptake both in early and late phase high retention index of 0.86

142 cells / $\mu \mathrm{L}$ (96\% lymphocytes);

glucose: $60 \mathrm{mg} / \mathrm{dL}$; total protein:

64 mg/dL; RPR titer: 1:2.4;

Treponema pallidum latex

agglutination titer: 1:53.4.;

fluorescent treponemal antibody

MRI: nodulus-enhanced temporal on T1,

hyperintense on T2; enhanced vestibulo-cochlear nerve and facial nerve $\mathrm{T} 1$.

absorption: $2+$ positive. 
Table 3. Cont.

\section{\# of Case}

Degenerative necrotic tissues and fibrous connective tissues with occasional perivascular infiltration by lymphocytes.
Fluorescent treponemal antibody absorption: increased (1:514.5)

\section{CSF}

\section{Neuroimaging}

Ref.

MRI: enhancing mass; iso to slightly hyperintense lesion (T1).

CT: iso-attenuating lesion; mild enhancement surrounding edema; hypointense with surrounding

edema (T2*); hypointensity at cortex with surrounding hyperintensity (DWI; postcontrast T1: heterogeneous enhancement).

CT perfusion: no increase in cerebral blood volume.

MRI: narrowing of the disc space at L4 -5 , mass behind vertebral body.

CT: "Extensive wormy appearance"

MRI: irregular-enhancing lesion with extensive edema. agglutination test: positive; RPR plasma cells). titer: 1:8.

CT: lesion frontal lobe with severe edema.

50 cells $/ \mu \mathrm{L}$ ( $80 \%$ lymphocytes, $20 \%$ monocytes); total protein level: $0.29 \mathrm{~g} / \mathrm{L}$; chloride concentration: $126.1 \mathrm{mmol} / \mathrm{L} ; \mathrm{RPR}+\mathrm{VDRL}$ : negative.

MRI: hyperintense gadolinium-enhanced T1-weighted regions in the brainstem.

MRI: enhancement of the left optic nerve.

Protein level: $0.72 \mathrm{~g} / \mathrm{L} ; \mathrm{RPR}$ : negative; TPPA: positive; Spirochetes: not detected.

MRI: mass lesion. of inflammatory cell infiltration (mainly of the plasma cells); Warthin-Starry staining: no spirochetes.

Granuloma with fibrous hyperplasia; large quantities of inflammatory cell infiltration; immunohistochemistry positive for GFAP, MBP, NF, CD3, and CD45RO; CD68 immunonegative: PAS and CD56; acid-fast staining: negative; Warthin-Starry staining: spirochete-positive. VDRL: 1:16 dilution; TPPA assay:
positive; very few cells; protein: $29 \mathrm{mg} / \mathrm{dL}$; glucose: $57 \mathrm{mg} / \mathrm{dL}$.
MRI: intramedullary nodule; isointense (T1);

hyperintense with isointense center, perilesional oedema (T2); lesion enhanced after contrast.

\section{Leukocyte count: 35 cells $/ \mathrm{mL}$} (2 neutrophils $/ \mathrm{mL}$,

33 lymphocytes $/ \mathrm{mL}$ ); total protein level: $30 \mathrm{mg} / \mathrm{dL}$; glucose: $59 \mathrm{mg} / \mathrm{dL}$; RPR titer: 1:<1; TPHA titer: 1:160; fluorescent treponemal antibody absorption titer: 1:32.
CT: hypodense lesion.

MRI: hypointense lesion by gadolinium-enhanced (T1), hyperintense (T2); extensive edema. 
Table 3. Cont.

\# of Case Histology

\section{CSF}

\section{Neuroimaging}

Ref.

Two lesions. MRI: low-signal (T1); ring-shaped

enhancement and blurry borders (contrast

enhanced); diffuse high-signal lesion (edema)

low-signal, high-signal border (T2).

CT: hypointense lesion, moderate edema. tissue (arrowhead)

Contrast-enhancing lesion with perifocal edema

This contrast enhancement. staining with antibodies to GFAP, p53, and IDH1-R132H negative. of a pathogen.

TPHA: CSF/serum index negative.

MRI: mass lesion.

White cells: 0/dL; erythrocytes:

Chronic inflammation; Warthin-Starry: no spirochetes; necrotic material $1 / \mathrm{mm}^{2}$; glucose: $74 \mathrm{mg} / \mathrm{dL}$; protein: infiltrated predominantly with plasma cells; peri-vascular region with $\quad 16.8 \mathrm{mg} / \mathrm{dL}$; VDRL test: negative; fibrosis contained lymphocytes and plasma cells; parenchymal T. pallidum infiltration of lymphocytes and plasma cells in the gumma.

(PCR): negative; FTA-ABS IgG: reactive.

MRI: irregular-enhancing mass, central necrosis; edema.

CT: mass-like lesion; severe swelling.

Protein: $0.468 \mathrm{~g} / \mathrm{L}$; chloride:

$133.2 \mathrm{mmol} / \mathrm{L}$; glucose: "normal",

Vascular intimal hyperplasia and large quantities of inflammatory cell infiltration; Warthin-Starry stain: T. pallidum-positive. T. pallidum"

"Aseptic meningitis" (lymphocytic pleocytosis, elevated protein, and normal glucose levels)

VDRL: positive; FTA: positive;

Ziehl-Neelsen stain: positive; protein: $0.37 \mathrm{~g} / \mathrm{L}$; glucose:

$4.0 \mathrm{mmol} / \mathrm{L}$; polymorphonuclear cells: 0 cells $/ \mathrm{mm}^{3}$; lymphocytes:

8 cells $/ \mathrm{mm}^{3}$; erythrocytes: 6 cells $/ \mathrm{mm}^{3}$.

28 Non-monoclonal, perivascular inflammatory infiltrates; no viral inclusions, granuloma or inclusions.
MRI: lesions with isointense signaling (T1);

White blood cells: 18; red blood cells: 350; VDRL: positive.

CT (with contrast): homogeneously
MRI: irregular nodulus; hypointense (T1)

hyperintense (T2) with meningeal thickening; edema. Contrast: enhancing ring.

MRI: Pontine lesion; isointense to gray matter

(T1WI); hyperintense on (T2WI and flair); no contrast enhancement.

MRI: Left sphenoid wing dural-based enhancing mass.

surrounding increased signal and mass effect (T2) enhancing lesions. 
Table 3. Cont.

\section{\# of Case}

Central portion of the mass: necrotic material infiltrated with eosinophils; peripheral portion: fibrotic0contained lymphocytes and plasma cells; Warthin-Starry staining: spirochete-positive.

\section{CSF}

\section{Neuroimaging}

Ref. blood cells: 3 cells $/ \mathrm{mm}^{3}$; glucose:

$$
65 \mathrm{mg} / \mathrm{dL} \text {; }
$$

protein level: $47.0 \mathrm{mg} / \mathrm{dL}$; VDRL, FTA-ABS; IgG: positive.

\section{Glucose, protein, and cell} counts: "Normal", VDRL: nonreactive.

MRI: mass with an ill-defined margin, accompanied

with severe swelling; central portion hypointense, peripheral isointense (T1); central portion

hyperintense, peripheral portion isointense (T2);

enhancement peripheral portion; no enhancement in the central portion (T1 contrast); high-signal intensity in the central portion (DWI).

MRI: Isodense lesion (T1); isointense, extensive perilesional edema (T2); enhanced uniformly in contrast.
Red blood cells: 0 cells $/ \mathrm{mm}^{3}$; white

$$
\text { syphilitic gumma. }
$$

Granulomatosis with inflammatory infiltration; reactional gliosis, especially in the perivascular space; Ziehl-Nielsen and Groccot staining. negative; T. pallidum: positive.

White blood cells: $2 / \mathrm{mm}^{3}$; protein

$26 \mathrm{mg} / \mathrm{dL}$; glucose: $69 \mathrm{mg} / \mathrm{dL}$

Intense lymphoproliferative infiltrates of plasma cells, T lymphocytes,

32 and B-cell infiltrates; PCR: positive for T. pallidum; Warthin-Starry stain: positive spirochaetes.

Necrotizing inflammatory mass, intense granulation; layered appearance:

outer layer of reactive glial tissue, middle layer of granulation tissue

containing lymphocytes, neutrophils, and plasma cells, and inner layer of necrosis; PCR: T. pallidum positive.
Aseptic meningitis with mononuclear pleocytosis; elevated protein with a low glucose CSF/serum ratio; RPR: positive.

"Normal cytology, glucose, and protein levels"; polymerase chain reactions for herpes simplex

cytomegalovirus, HHV6, and enteroviruses: negative;

anti-treponemal antibodies: positive VDRL: negative.

MRI: lesion enhanced in contrast.

VDRL: reactive.

CT: left frontal lobe mass.

$$
\text { VDRL: positive. }
$$

MRI: cortical lesion, isointense (T1, T2,

fluid-attenuated inversion); edema; nodular and

meningeal enhancement (contrast); restricted
Syphilitic gumma on postmortem neuropathologic examination: well-defined, round, rubbery, gray-tan, $4 \mathrm{~cm}$ maximal diameter mass, with adjoining diffuse edema; diffuse thickening of leptomeninges and infiltration with lymphocytes and plasma cells peri-vascularly, and histiocytes within leptomeninges; Warthin-Starry and modified Steiner

CT: without contrast left middle cerebral artery infarct, with edema and mass effect. stain did not demonstrate treponemas. 
Table 3. Cont.

\section{\# of Case}

Histology

\section{CSF}

Neuroimaging

Ref.

White blood cell count: $1010 / \mu \mathrm{L}$

(64\% polymorphonuclear

leukocytes); hypoglycorrhachia:

$16 \mathrm{mg} / \mathrm{dL}$; protein level: $0.17 \mathrm{~g} / \mathrm{dL}$

lactate level: $50 \mathrm{mg} / \mathrm{dL}$; IgG index:

1.27; 16 oligoclonal bands;

anti-treponemal antibodies: positive

VDRL: positive.

MRI: vasogenic edema; enhancement of gumma (contrast), edema.

MRI: heterogeneous enhancement of partially cystic midline butterfly-shaped intra- and extra-axial mass; edema; butterfly midline lesion with mild

Necrotic areas with extensive mixed inflammation, consisting of lymphocytes, plasma cells, neutrophils, and focal collagen deposits; inflammation was also present in several midsized arteries, with extensive infiltration by macrophages and severe narrowing of the lumens.

regions within the lesion and surrounding

inflammation and edema (FLAIR); no hyperintensity in the lesion (DWI).

T: heterogeneous perifalcine mass extending from the corpus callosum bilaterally into the subcortical

regions of the frontal lobes with considerable mass effect.

26 cells $/ \mathrm{mm}^{3}$ (94\% lymphocytes);

protein level: $106 \mathrm{mg} / \mathrm{dL}$; glucose

level: $65 \mathrm{mg} / \mathrm{dL}$; VDRL and FTA-ABS: reactive.

MRI: contrast-enhancing lesions

Autopsy: rich lymphocytes and

plasma cells around blood vessels a

CT: three-ringed space-occupying lesions, he border of the gummas. surrounding edema.

MRI: hypointense lesion (T1, T2), and strongly

enhanced (contrast)

CT: irregular low-density, ring-like

TPHA: positive. 
Table 3. Cont.

\section{\# of Case}

Histology

\section{CSF

CSF

Neuroimaging

Ref.

Protein level: $117 \mathrm{mg} / \mathrm{dL}$; glucose

level: $69 \mathrm{mg} / \mathrm{dL}$; white blood cells

11 per $\mathrm{mm}^{3}$ (82\% lymphocytes and

$18 \%$ polymorphonuclear cells); VDRL: positive. tissue infiltrated with proliferating fibroblasts, variable numbers of

lymphocytes, macrophages, and histiocytes, and many newly formed small blood vessels; perivascular lymphocytes and histiocytes.
Necrotic center, surrounded by a layer of granulation

MRI: “abnormal signal” (T2); multifocal contrast enhancement.

CT: Small ring-like enhanced mass with surrounding low-density area.

MRI: low-signal-intensity basal ganglia (T1); small ring-like enhancement in the vicinity of the right optic nerve (contrast); high-signal intensity surrounding the lesion (T2).

CT: ambiguous hypodense lesions; oval homogeneously contrast-enhanced mass lesion attached to the dura mater right temporal.

MRI: low-intensity lesions in right cerebellar

hemisphere, right middle cerebellar peduncle, and right temporal lobe (T1); and high intensity in T2

homogeneously enhanced (contrast).

Three years ago: white blood cells:

$4 / \mathrm{mm}^{3}$ (lymphocytes); erythrocytes:

Postmortem: lesions with rubbery greenish core, surrounded by darker area; necrosis with marked inflammatory exudate (lymphocytes and
plasma); multinucleated giant cells; silver staining with modified Steine stain: spirochetal forms; PCR of coded specimens: syphilis (confirmed with DNA hybridization).
$3 / \mathrm{mm}^{3}$; protein level: $140 \mathrm{mg} / \mathrm{dL}$; glucose level: $40 \mathrm{mg} / \mathrm{dL}$;

Last admission: white blood cells:

$12 / \mathrm{mm}^{3}$ (11 lymphocytes);

erythrocytes: 0; glucose level:

$50 \mathrm{mg} / \mathrm{dL}$; protein level:

$178 \mathrm{mg} / \mathrm{dL}$; VDRL: positive. 
Table 3. Cont

\section{\# of Case}

CSF

Protein level: $23 \mathrm{mg} / \mathrm{dL}$; glucose

level: $86 \mathrm{mg} / \mathrm{dL}$; leukocytes:

$28 / \mathrm{mm}^{3}$; erythrocytes: $2 / \mathrm{mm}^{3}$.

$$
\text { VDRL: not recorded. }
$$

Second CSF sampling after one

month: protein level: $82 \mathrm{mg} / \mathrm{dL}$;

glucose level: $60 \mathrm{mg} / \mathrm{dL}$; leukocytes:

$38 / \mathrm{mm}^{3}(99 \%$

lymphocytes); VDRL: positive. Third lumbar puncture after five months (after therapy):

protein level: $40 \mathrm{mg} / \mathrm{dL}$; glucose

level: $55 \mathrm{mg} / \mathrm{dL}$; leukocytes:

$13 / \mathrm{mm}^{3}$ (86\% lymphocytes);

VDRL: positive.

MRI: contrast-enhancing lesions (T1); edema. One month later:

CT: substantial resolution of the lesions while the patient was receiving only corticosteroid therapy (contrast)

Nine months later:

MRI: after treatment with both antibiotics and corticosteroids, demonstrated resolution of the lesions, except for a subtle abnormality in the left midbrain $(\mathrm{Tl}+$ contrast $)$.

MRI: dural thickening in the area of the lesion.

CT: isolated, peripherally located, contrast-enhancing lesion of the brain.

CT: isolated, peripherally located contrast-enhancing lesion of the brain.

"Increased lymphocytes, elevated protein, and decreased glucose."

Second lumbar puncture: FTA-ABS: positive.

(T1 + double spin echo); enhanced markedly

$$
\text { (T1, contrast). }
$$

CT: suprasellar enhancing mass.

MRI: intense enhancement

Erythrocytes: 6 ; lymphocytes: 0 ;

glucose level: 41; protein level: 83 ;

culture: negative; VDRL: positive

(units are not reported). 


\section{Discussion}

Although reports of intracerebral gummata are rare [9], the increasing reports of syphilis suggest that healthcare professionals will encounter an increasing number of cerebral manifestations, as shown by our review. With this case report and review, we aim to raise awareness of the resurgence of this well-known, but mostly historical, disease that should be considered in the differential diagnosis of intracerebral lesions.

Author Contributions: L.B. designed, wrote, edited, validated, and reviewed the manuscript, carried out the scientific literature search, developed the figures, and was responsible for project administration and funding acquisition. S.H. wrote, edited, and reviewed the manuscript, carried out the scientific literature search, and acquired the funding. S.T.-H. performed histopathological analyses and prepared the histopathological figures. V.C. oversaw the microbiological analyses. U.S. supervised and carried out a critical review and commentary. L.B. and U.S. cared for the patient. L.B. and S.H. contributed equally. All authors have read and agreed to the published version of the manuscript.

Funding: This work was supported by the Internal Research Funding (IFORES) of the University Hospital Essen (D/107-41030 to SH) and the University Medicine Essen Clinician Scientist Academy and Deutsche Forschungsgemeinschaft (DFG) (D/107-21930 to LB).

Institutional Review Board Statement: Not applicable.

Informed Consent Statement: Written informed consent for publication was obtained from the patient. This research was conducted in accordance with the 1964 Declaration of Helsinki.

Data Availability Statement: The collected data and references are listed in this case report.

Conflicts of Interest: The authors in this article have no conflict of interest to disclose.

Search Criteria: The authors identified references using a search of the EMBASE, Google Scholar, and Medline (PubMed) databases for English language-only articles published between 1989 and December 2019 using the following terms: "Syphilis," "Treponema pallidum," "Syphilis MSM," "Syphilis men who have sex with men," "Treponema pallidum central nervous system," "Syphilis Western countries," "Epidemiology syphilis," ‘Epidemiology Treponema pallidum," “Transmitted sexual diseases," "STD," "STI," "Treponema pallidum brain," "Treponema pallidum CNS," "Treponema pallidum head," "Gumma syphilis," “Gumma central nervous system," “Gumma CNS," “Gumma brain," “Gumma intramedullary," "Syphilis tumour," and "Syphilis tumor." The authors also reviewed the websites of the United States Centers for Disease Control and Prevention, the European Centre for Disease Prevention and Control, the Robert Koch Institute (German federal government agency and research institute responsible for disease control and prevention), and UpToDate, Inc. (Wolters Kluwer, Alphen aan den Rijn, Netherlands). The databases were analyzed by two authors independently of one another using these search criteria.

\section{References}

1. Church, B.; Wall, E.; Webb, J.R.; Cameron, C.E. Interaction of treponema pallidum, the syphilis spirochete, with human platelets. PLOS ONE 2019, 14, 1-22. [CrossRef]

2. Margos, G.; Gofton, A.; Wibberg, D.; Dangel, A.; Marosevic, D.; Loh, S.M.; Oskam, C.; Fingerle, V. The genus Borrelia reloaded. PLoS ONE 2018, 13, 1-14. [CrossRef] [PubMed]

3. Pónyai, K.; Ostorházi, E.; Marschalkó, M.; Kárpáti, S.; Rozgonyi, F. Syphilis: Today. Rev. Med. Microbiol. 2010, 21, 84-95. [CrossRef]

4. Ojcius, D.; Peeling, R.W.; Mabey, D.C.W. In the news/focus: Syphilis. Nat. Rev. Microbiol. 2004, 2, 448-449. [CrossRef]

5. CDC Syphilis \& MSM (Men who have Sex with Men). CDC Fact Sheet. STD Facts 2019, 1-2, 1.

6. Marra, C.M.; González-Scarano, F.; Jeanne, M. Neurosyphilis-UpToDate. Available online: https://www.uptodate.com/ contents / neurosyphilis?search=neurosyphilis\&source=search_result\&selectedTitle $=1 \sim\{\} 70 \& u s a g e \_t y p e=d e f a u l t \& d i s p l a y \_$ rank=1 (accessed on 4 March 2020).

7. Ropper, A.H. Neurosyphilis. N. Engl. J. Med. 2019, 381, 1358-1363. [CrossRef]

8. Tien, R.D.; Gean-Marton, A.D.; Mark, A.S. Neurosyphilis in HIV carriers: MR findings in six patients. Am. J. Roentgenol. 1992, 158, 1325-1328. [CrossRef]

9. Thibodeau, R.; Goel, A.; Jafroodifar, A.; Klumpp, M.; Mirchia, K.; Swarnkar, A. Cerebral syphilitic gumma presenting with intracranial gumma and pathologic vertebrae fractures. Radiol. Case Rep. 2021, 16, 916-922. [CrossRef]

10. Weng, C.; Huang, K.; Jiang, T.; Zhou, G.; Wu, T. Cerebral syphilitic gumma masquerading as cerebral metastatic tumors: Case report. Neurosurg. Focus 2019, 47. [CrossRef] 
11. Tawfik, S.; Khong, P.; Dower, A.; Huynh, W. Syphilitic gumma presenting as myelopathy. J. Clin. Neurosci. 2019, 10-11. [CrossRef]

12. Shen, S.; Yang, R.; Wang, L.; Tang, L.; Liu, B. Multiple intracranial and spinal cord syphilitic gummas in a human immunodeficiency virus-negative man with untreated syphilis: A case report. Medicine 2019, 98, e16887. [CrossRef] [PubMed]

13. Sasaki, R.; Tanaka, N.; Okazaki, T.; Yonezawa, T. Multiple cerebral syphilitic gummas mimicking brain tumor in a non-HIVinfected patient: A case report. J. Infect. Chemother. 2019, 25, 208-211. [CrossRef] [PubMed]

14. Huang, Y.H.; Shi, Q.X.; Xu, M.M.; Chen, C.Z.; Yang, M.L.; Li, J.J.; Chen, Y.F.; Lin, Z.Q.; Lin, Y.Y. Spinal cord syphilitic gumma presenting with brown-Séquard syndrome: A case report and literature review. Ann. Clin. Lab. Sci. 2019, 49, 265-270. [PubMed]

15. Shao, X.; Qiang, D.; Liu, Y.; Yuan, Q.; Tao, J.; Ji, B. Diagnosis and Treatment of Cerebral Syphilitic Gumma: A Report of Three Cases. Front. Neurosci. 2018, 12, 1-6. [CrossRef]

16. Kuroi, Y.; Tani, S.; Shibuya, M.; Kasuya, H. Teaching NeuroImages: Cerebral syphilitic gumma with numerous spirochetes in immunohistochemical staining. Neurology 2018, 90, e818-e819. [CrossRef]

17. Koizumi, Y.; Watabe, T.; Ota, Y.; Nakayama, S.I.; Asai, N.; Hagihara, M.; Yamagishi, Y.; Suematsu, H.; Tsuzuki, T.; Takayasu, M.; et al. Cerebral Syphilitic Gumma Can Arise Within Months of Reinfection: A Case of Histologically Proven Treponema pallidum Strain Type 14b/f Infection with Human Immunodeficiency Virus Positivity. Sex. Transm. Dis. 2018, 45, e1-e4. [CrossRef]

18. Kodama, T.; Sato, H.; Osa, M.; Fujikura, Y.; Kawana, A. Cerebral syphilitic gumma in immunocompetent man, Japan. Emerg. Infect. Dis. 2018, 24, 395-396. [CrossRef]

19. Kikuchi, Y.; Hiwatashi, A.; Togao, O.; Yamashita, K.; Momosaka, D.; Honda, H. Cerebral syphilitic gumma mimicking glioma: Utility of CT perfusion. Diagn. Interv. Imaging 2018, 99, 755-757. [CrossRef]

20. Yin, R.; Wang, L.; Zhang, T.; Zhao, B. Syphilis of the lumbar spine: A case report and review of the literature. Medicine 2017, 96, e9098. [CrossRef]

21. Xia, D.Y.; Zhu, M.F.; Liu, C.G.; Dai, Y.; Li, Z.B.; Jiang, X.C.; Xu, S.S. Cerebral Syphilitic Gumma Misdiagnosed as a Malignant Brain Tumor. J. Craniofac. Surg. 2017, 28, e170-e172. [CrossRef]

22. Shi, F.; Jiang, H.; Shi, Z.; Liu, H.; Zhang, Q. Cerebral syphilitic gumma: Case report of a brainstem mass lesion and brief review of the literature. Jpn. J. Infect. Dis. 2017, 70, 595-596. [CrossRef]

23. Rasool, N.; Stefater, J.A.; Eliott, D.; Cestari, D.M. Isolated presumed optic nerve gumma, a rare presentation of neurosyphilis. Am. J. Ophthalmol. Case Rep. 2017, 6, 7-10. [CrossRef]

24. Zhang, L.; Zhou, Y.; Chen, J.; Yan, W.; Kong, Q.; Chen, P.; Sang, H. A case of a cerebral syphilitic gumma developed in a few months mimicking a brain tumor in a human immunodeficiency virus-negative patient. Br. J. Neurosurg. 2016, 31, 481-483. [CrossRef]

25. Yang, C.; Li, G.; Fang, J.; Liu, H.; Yang, B.; Xu, Y. Spinal Intramedullary Syphilitic Gumma: An Unusual Presentation of Neurosyphilis. World Neurosurg. 2016, 95, e17-e23. [CrossRef]

26. Tsuboi, M.; Nishijima, T.; Teruya, K.; Kikuchi, Y.; Gatanaga, H.; Oka, S. Cerebral syphilitic gumma within 5 months of syphilis in HIV-infected patient. Emerg. Infect. Dis. 2016, 22, 1846-1848. [CrossRef] [PubMed]

27. Faropoulos, K.; Zolota, V.; Gatzounis, G. Occipital lobe gumma: A case report and review of the literature. Acta Neurochir. 2017, 159, 199-203. [CrossRef] [PubMed]

28. Sprenger, K.; Furrer, H. Chameleons everywhere. BMJ Case Rep. 2014, 2014, 1-3. [CrossRef] [PubMed]

29. Yoon, Y.K.; Kim, M.J.; Chae, Y.S.; Kang, S.H. Cerebral syphilitic gumma mimicking a brain tumor in the relapse of secondary syphilis in a human immunodeficiency virus-negative patient. J. Korean Neurosurg. Soc. 2013, 53, 197-200. [CrossRef]

30. Huo, K.; Liu, L. Horizontal gaze palsy with progressive myoclonic epilepsy: Rare presentation of Gaucher's disease. Neurol. India 2013, 61, 177-178. [CrossRef]

31. Ventura, N.; Cannelas, R.; Bizzo, B.; Gasparetto, E.L. Intracranial syphilitic gumma mimicking a brain stem glioma. Am. J. Neuroradiol. 2012, 33, 110-111. [CrossRef]

32. Noel, C.B.; Moeketsi, K.; Kies, B. Cavernous sinus syndrome, an atypical presentation of tertiary syphilis: Case report and review of the literature. Clin. Neurol. Neurosurg. 2011, 113, 65-67. [CrossRef]

33. Li, J.C.; Mahta, A.; Kim, R.Y.; Saria, M.; Kesari, S. Cerebral syphilitic gumma: A case report and review of the literature. Neurol. Sci. 2012, 33, 1179-1181. [CrossRef]

34. Lee, C.W.; Lim, M.J.; Son, D.; Lee, J.S.; Cheong, M.H.; Park, I.S.; Lim, M.K.; Kim, E.; Ha, Y. A case of cerebral gumma presenting as brain tumor in a human immunodeficiency virus (HIV)-negative patient. Yonsei Med. J. 2009, 50, 284-288. [CrossRef]

35. Fargen, K.M.; Alvernia, J.E.; Lin, C.S.; Melgar, M. Cerebral syphilitic gummata: A case presentation and analysis of 156 reported cases. Neurosurgery 2009, 64, 568-575. [CrossRef]

36. Weinert, L.S.; Scheffel, R.S.; Zoratto, G.; Samios, V.; Jeffmann, M.W.; Dora, J.M.; Goldani, L.Z. Cerebral syphilitic gumma in HIV-infected patients: Case report and review. Int. J. STD AIDS 2008, 19, 62-64. [CrossRef]

37. Morshed, M.G.; Lee, M.K.; Maguire, J.; Zwimpfer, T.; Willoughby, B.; Clement, J.; Crawford, R.I.; Barberie, J.; Gul, S.; Jones, H. Neurosyphilitic gumma in a homosexual man with HIV infection confirmed by polymerase chain reaction. Int. J. STD AIDS 2008, 19, 568-569. [CrossRef]

38. Darwish, B.S.; Fowler, A.; Ong, M.; Swaminothan, A.; Abraszko, R. Intracranial syphilitic gumma resembling malignant brain tumour. J. Clin. Neurosci. 2008, 15, 308-310. [CrossRef] 
39. Soares-Fernandez, J.; Ribeiro, M.; Mare, R.; Magalhaes, Z.; Lourenco, E.; Rocha, J. Diffusion-Weighted Magnetic Resonance Imaging Findings in a Patient with Cerebral Syphilitic Gumma. J. Comput. Assist. Tomogr. 2007, 31, 592-594. [CrossRef]

40. Gyori, E.; Lew, E.O. Unsuspected central nervous system gummas in a case of "cerebral infarctg" associated with cocaine use. Am. J. Forensic Med. Pathol. 2007, 28, 208-211. [CrossRef]

41. Régal, L.; Demaerel, P.; Dubois, B. Cerebral syphilitic gumma in a human immunodeficiency virus-positive patient. Arch. Neurol. 2005, 62, 1310-1311. [CrossRef]

42. Ances, B.; Danish, S.; Kolson, D.; Judy, K.; Liebeskind, D. Cerebral Gumma Micking Glioblastoma Multiforme. Neurocrit. Care 2005, 2, 300-302. [CrossRef]

43. Lana-Peixoto, M.; Teixeira, A.J.; Tzelikis, P.; Campos, W.; Curi, A.; Orefice, F. Asymptomatic Intracranial Gumma in a Patient with Syphilitic Uveitis and Human Immunodeficiency Infection. Scand. J. Infect. Dis. 2003, 35, 341-343. [CrossRef]

44. Charach, G.; Groskopf, I.; Turner, D.; Barilan, M.; Kugel, C.; Weintraub, M. Syphilitic Gumma and Tubercolosis: An Unusual Combination in AIDS. Case Commun. 2008, 10, 1-2.

45. Takeshima, H.; Kaku, T.; Ushio, Y. Cerebral Gumma showing spontaneous regression on magnetic resonance imaging study. Neurol. Med. Chir. 1999, 39, 242-245. [CrossRef]

46. Suarez, J.; Mlakar, D.; Snodgrass, S. Cerebral Syphilitic Gumma in an HIV-Negative Patient Presenting as Prolonged Focal Motor Status Epilepticus. N. Engl. J. Med. 1996, 335, 1159-1160. [CrossRef]

47. Uemura, K.; Yamada, T.; Tsukada, A.; Enomoto, T.; Yoshii, Y.; Nose, T. Cerebral Gumma Mimicking Resonance Glioblastoma Images on Magnetic. Neurol. Med. Chir. 1995, 35, 462-466. [CrossRef]

48. Inoue, R.; Katayama, S.; Kusakabe, T.; Mori, T.; Hori, S. Cerebral Gumma Showing Linear Dural Enhancement on Magnetic Resonance Imaging. Neurol. Med. Chir. 1995, 35, 813-817. [CrossRef]

49. Horowitz, H.; Valsamis, M.; Wicher, V.; Abbruscato, F.; Larsen, S.; Wormser, G.; Wicher, K. Brief Report: Cerebral Syphilitic Gumma Confirmed by The Polymerase Chain Reaction in a Man with Human Immunodeficiency Virus Infection. N. Engl. J. Med. 1994, 331, 1488-1491. [CrossRef]

50. Herrold, J.M. A Syphilitic Cerebral Gumma Manifesting as a Brain-Stem Mass Lesion That Responded to Corticosteroid Monotherapy. Mayo Clin. Proc. 1994, 69, 960-961. [CrossRef]

51. Berger, J.R.; Waskin, H.; Pall, L.; Hensley, G.; Ihmedian, I.; Post, M.J.D. Syphilitic cerebral gumma with HIV infection. Neurology 1992, 42, 1282-1287. [CrossRef]

52. Wang, A.M.; Barriger, T.K.; Wesolowski, D.P. Intracranial gumma mimicking a tuber cinereum tumor. Comput. Med. Imaging Graph. 1991, 15, 57-60. [CrossRef]

53. Standaert, D.G.; Galetta, S.L.; Atlas, S.W. Meningovascular syphilis with a gumma of the midbrain. J. Clin. Neuroophthalmol. 1991, 11, 139-143. [PubMed]

54. Smith, J.L.; Byrne, S.F.; Cambron, C.R. Syphiloma/gumma of the optic nerve and human immunodeficiency virus seropositivity. J. Clin. Neuroophthalmol. 1990, 10, 175-184. [PubMed] 